\title{
Myco-Fabricated Gold Nanoparticles from Aspergillus tamarii MTCC5152, its Characterization and Dye Biodegradation
}

\author{
Ragavy Radhakrishnan ${ }^{1}$, Uthirappan Mani $^{2}$, Arumugam Gnanamani ${ }^{1}$, Muthiah Shanmugavel ${ }^{1^{*}}$ (i) \\ ${ }^{1}$ Microbiology Division, CSIR-Central Leather Research Institute, Chennai, 600020, India \\ ${ }^{2}$ Biochemistry and Biotechnology Division, CSIR-Central Leather Research Institute, Chennai, 600020, India \\ Email: shanmugavel@clri.res.in; shanmugavel_m_2001@yahoo.com
}

Received: 20 February 2021; Revised: 16 June 2021; Accepted: 22 July 2021

\begin{abstract}
This work was initiated to investigate the myco-fabrication of gold nanoparticles (AuNPs) using a fungal strain, Aspergillus tamarii 5152 (A. tamarii MTCC 5152). The biosynthesized gold nanoparticles were characterized by visual observation, and using UV-Vis and Fourier transform infrared spectroscopy (FTIR) spectroscopy, Differential scanning calorimetry (DSC), Thermogravimetric analysis (TGA), Zeta-potential, Dynamic light scattering (DLS) and Scanning Electron Microscopy (SEM) analyses. NADH-dependent cofactor analysis and photocatalysis assays were carried out for Nicotinamide adenine dinucleotide (NADH)-dependent AuNPs biosynthesis and dye degradation ability. A maximum surface plasmon resonance peak for the AuNPs was recorded at $535 \mathrm{~nm}$, followed by the identification of protein capping effect of the extract by FTIR spectroscopy. The average size (Z) of the nanoparticles observed was $39.15 \mathrm{~nm}$, while SEM images showed crystallized rod-shaped structures ranging from 55-91 nm. A negative zeta potential of $10.5 \mathrm{mV}$ showed repulsion between the nanoparticles, which indicates the stabilizing power of the fungal extract. Further, it was observed that NADH acts as a cofactor for the nanoparticle biosynthesis. The AuNPs were found to degrade crystal violet dye by $63 \%$. From this study, it can be understood that the process of fungal mediated biosynthesis of AuNPs by A. tamarii MTCC 5152 is simple, less expensive, and could be utilized for bioremediation of toxic dye accumulation.
\end{abstract}

Keywords: Aspergillus tamarii MTCC 5152, myco-fabrication, gold nanoparticles, NADH, photocatalysis

\section{Introduction}

Gold nanoparticles (AuNPs) have significant roles in biological applications [1-5]. Due to the stability under atmospheric conditions and the resistance to oxidation and biocompatibility [6-7], gold nanoparticles are suitable candidates in almost all fields of medical sciences, including diagnostics, therapy, preventive medicine and hygiene. The existing physical and chemical methods of nanoparticle synthesis [8-11] have many disadvantages due to the release of hazardous by-products [12]. Hence, the development of an environment-friendly, biological non-toxic method utilizing plants and microbes are gaining attention in the present day research setting [13]. Among the microbes, only very few fungal species have been reported with respect to the synthesis of AuNPs. The nanoparticle synthesis by filamentous fungi have numerous advantages with trouble-free processing and feasible scale-up process. These myco-fabricated

Copyright (C2021 Muthiah Shanmugavel, et al.

DOI: https://doi.org/10.37256/amtt.222021792

This is an open-access article distributed under a CC BY license

(Creative Commons Attribution 4.0 International License)

https://creativecommons.org/licenses/by/4.0/ 
AuNPs are cost-efficient, easy to synthesize and relatively less hazardous. Fusarium sp. [14], Yeast Yarrowia lipolytica [15], Candida albicans [16], Fusarium oxysporum and Penicillium sp. [17], Neurospora crassa [18], Candida utilis, Verticillium luteoalbum, Phanerochaete chrysosporium and Phomaexigua NCIM 1237 [19] and Trichoderma reesei NCIM 1186 [20] are some notable fungi that are accounted for the synthesis of AuNPs.

The genus Aspergillus is considered to be one among the most important filamentous fungi. Their prevalence in the natural environment and ease of cultivation have been extensively studied. There are also existing reports with reference to gold nanoparticle synthesis namely A. clavatus [21], A. flavus NCIM 650, A. niger NCIM 616, A. niger NCIM 1025 [20]. A. tamarii MTCC 5152, a potential fungus, has a demonstrated role in the biosynthesis of silver nanoparticles [22]. However, there are no reports traced on their use in biosynthesis of AuNPs. Therefore, the present study has been taken up to explore the efficacy of $A$. tamarii MTCC 5152 for the synthesis of AuNPs.

\section{Experimental section}

\subsection{Biosynthesis of AuNPs using A. tamarii MTCC 5152}

All chemicals used throughout the experiments were of analytical grade. Gold chloride $\left(\mathrm{HAuCl}_{4}\right)$ was purchased from Sisco Research Laboratories Pvt. Ltd., India. The fungus, A. tamarii MTCC 5152 was isolated from tannery effluent and was deposited at the Microbial Type Culture Collection and Gene bank, CSIR-Indian Institute of Microbial Technology, Chandigarh, India. A. tamarii MTCC 5152 was grown under aerobic conditions in $250 \mathrm{~mL}$ Erlenmeyer flasks containing $100 \mathrm{~mL}$ of growth medium comprising Yeast extract $(0.6 \mathrm{~g})$, Potassium dihydrogen phosphate $(0.7 \mathrm{~g})$, dipotassium hydrogen phosphate $(0.2 \mathrm{~g}), \mathrm{MgSO}_{4} \cdot 7 \mathrm{H}_{2} \mathrm{O}(0.01 \mathrm{~g}),\left(\mathrm{NH}_{4}\right)_{2} \mathrm{SO}_{4}(0.1 \mathrm{~g})$ and glucose $(1 \mathrm{~g})$. The culture was incubated in an orbital shaker at $150 \mathrm{rpm}$ in the temperature range of $30{ }^{\circ} \mathrm{C}$. After six days, the biomass was separated from the culture medium, using a suction pump and a Whatman paper, applying the principle of filtration. The biomass was then repeatedly rinsed using distilled water to remove any medium components and residues, if present. About $10 \mathrm{~g}$ of biomass was weighed and suspended in $100 \mathrm{~mL}$ of Milli Q water in $250 \mathrm{~mL}$ Erlenmeyer flask and maintained under agitated condition at $250 \mathrm{rpm}$ for $72 \mathrm{~h}$ at $30{ }^{\circ} \mathrm{C}$. The entire process was carried out in a dark environment. The fungal extract was suspended in $90 \mathrm{~mL}$ of $20 \mathrm{mM}$ potassium phosphate buffer ( $\mathrm{pH} 7.0)$ and $10 \mathrm{~mL}$ of $1 \mathrm{mM} \mathrm{HAuCl}_{4}$, taken in a ratio of 9:1 (v/v) was incubated at $30^{\circ} \mathrm{C}$ for $24 \mathrm{~h}$. The optimized conditions for the biosynthesis of AuNPs are given in the Supplementary data.

\subsection{Characterization of AuNPs}

With the appearance of visible color change, the preliminary confirmation of fungus-mediated AuNPs was carried out by using UV-visible double beam spectrophotometer (Shimadzu UV-2450). The AuNPs extracted from A. tamarii MTCC 5152 were centrifuged and frozen dried. The dried sample grounded with Potassium Bromide (KBr) was subjected to FTIR analysis (JASCO FTIR-4700, Japan) for identification of the product where infrared rays analyze the functional groups at characteristic wavelengths. The spectrum was recorded in the range of $4000-400 \mathrm{~cm}^{-1}$, at a resolution of $4 \mathrm{~cm}^{-1}$. The thermal characteristics of the synthesized gold nanoparticles were analysed by using TGA (SDT Q600, TA Instruments, New Castle, USA) and DSC (DSC Q200, V24.10 Build 122). The particle size distribution of nanoparticles was observed by using Dynamic Light Scattering (Malvern Instruments Ltd, Malvern, UK), followed by SEM analysis (TESCAN MAGNA, Czech Republic) and finally Zeta potential (Malvern Instruments Ltd., Malvern, UK) was determined.

The increasing industrialization have caused an alarming rate of increasing environmental concerns such as the heavy damage to the ecosystem by adding up herbicide by-products such as 4-nitrophenol and polluting dyes inclusive of anionic and cationic dyes, from the textile firms. Considering the fact that metal nanoparticles possess high surface area to volume ratio and high surface absorption ability, they can be used as a useful catalytic agent and in the environmental remediation [23]. The role of NADH-dependent reductase in the reduction of $\mathrm{Au}^{+}$into AuNPs and photocatalytic activity of the nanoparticles, in terms of degradation of a toxic dye [24], were also studied. In this study, crystal violet was used as the model dye, taken at a concentration of $10 \mathrm{mg} / \mathrm{L}^{-1}$ [25]. Two study systems were taken; a control system with only crystal violet solution $(10 \mathrm{~mL})$ and another containing $10 \mathrm{~mL}$ of crystal violet solution with 10 $\mathrm{mg}$ of the myco-synthesized gold nanoparticles; and were kept under direct sun light. At regular intervals, aliquots were 
taken and absorbance was measured. The following equation was applied to determine the percentage of dye degraded:

$$
\% \text { Dye deg radation }=\frac{(\text { Initial Optical Density }- \text { Final Optical Density })}{\text { Initial Optical Density }} \times 100
$$

\section{Results and discusion}

The appropriate conditions for AuNP synthesis were determined in different concentrations of fungal biomass extracts with different concentration of AuNPs solutions under varying $\mathrm{pH}$ conditions. A visible color change of auric chloride from golden to deep red color (Figure 1) at $1 \mathrm{mM}$ concentration ( $\mathrm{pH} 5.5)$ was observed. A similar study on the different process parameters, including concentration of the extract, mixing ratio and interaction time, for synthesizing AuNPs was reported by Anjana (2015), which was similar to our observation [26].

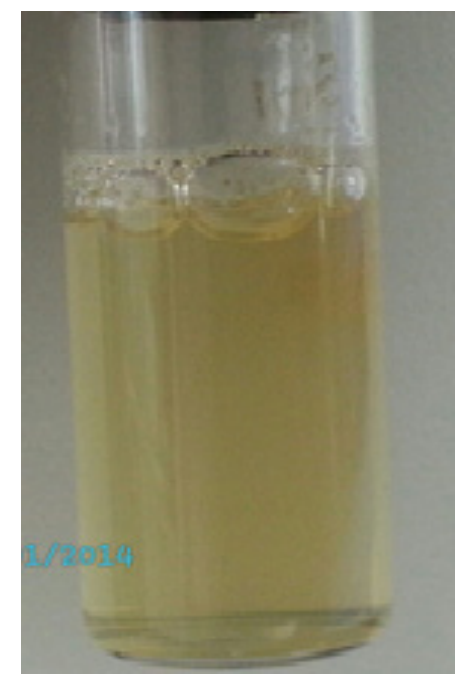

(a)

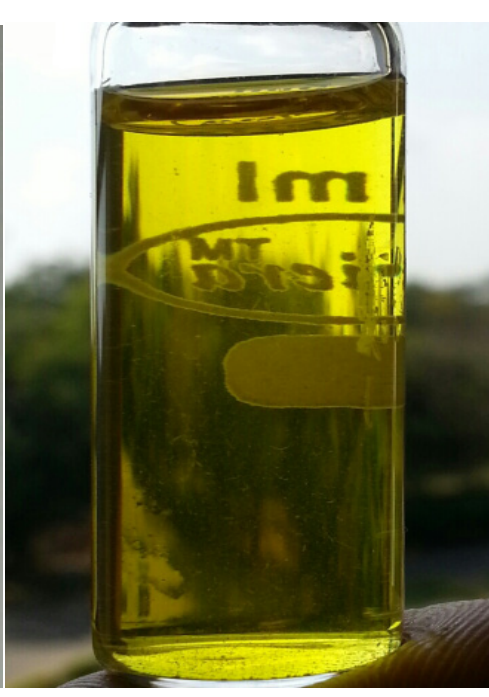

(b)

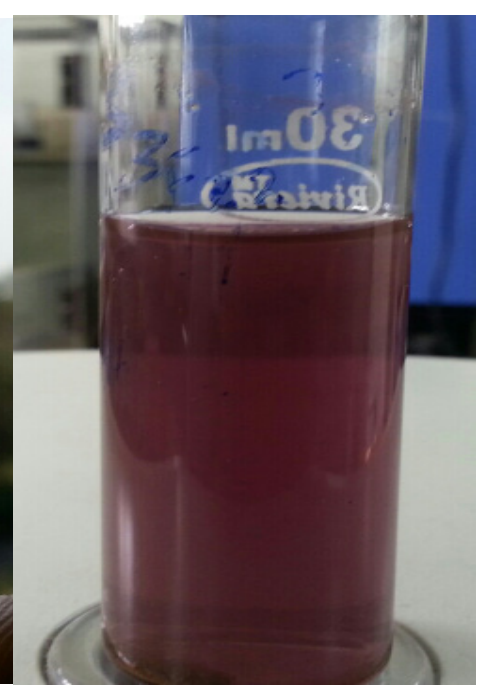

(c)

Figure 1. Images on (a) Fungal cell-free filtrate (b) $1 \mathrm{mM} \mathrm{HAuCl}_{4}$ solution (c) formation of gold nanoparticles

AuNPs possess a unique electronic property termed the localized surface plasmon resonance, which can be used for the characterization of the synthesized AuNPs, since this property is absent when gold is present as a whole [27]. The synthesized AuNPs were characterized by using UV-visible spectroscopy, wherein the absorption spectra of AuNPs formed in the reaction medium showed surface plasmon resonance at $535 \mathrm{~nm}$ (Figure 2). The absorption peak at $535 \mathrm{~nm}$ was noticed at a time period of $24 \mathrm{~h}$ and reached the maximum intensity after $72 \mathrm{~h}$. The similar type of result was also observed by Priyadarshini et al. [28] and Namita Soni et al. [29] in Aspergillus spp.

Micro size of AuNPs is highly unstable in nature. Hence, the fungal proteins (organic in nature) are known to stabilize the nanoparticles by acting as a capping agent. This stabilization can be determined by FTIR, based on the interactions involved between the various chemical groups present [28]. FTIR spectra of AuNPs synthesized by A. tamarii MTCC 5152 showed peaks at 3385, 2922, 1639 and $1038 \mathrm{~cm}^{-1}$. A very strong peak at $3385 \mathrm{~cm}^{-1} \mathrm{can} \mathrm{be}^{-1}$ associated with $\mathrm{O}-\mathrm{H}$ stretching vibration. The absorption peak at $1639 \mathrm{~cm}^{-1}$ corresponds to amide I arising due to the carbonyl stretch vibration in the amide linkage of protein, indicating that the synthesized AuNPs are possibly bound to proteins (Figure 3). The different vibrational stretches of the FTIR measurement were confirmed based on the previous reports [29-30], where bands at $3385.76 \mathrm{~cm}^{-1}$ correspond to primary amines and $1639.79 \mathrm{~cm}^{-1}$ correspond to carbonyl group [31]. 


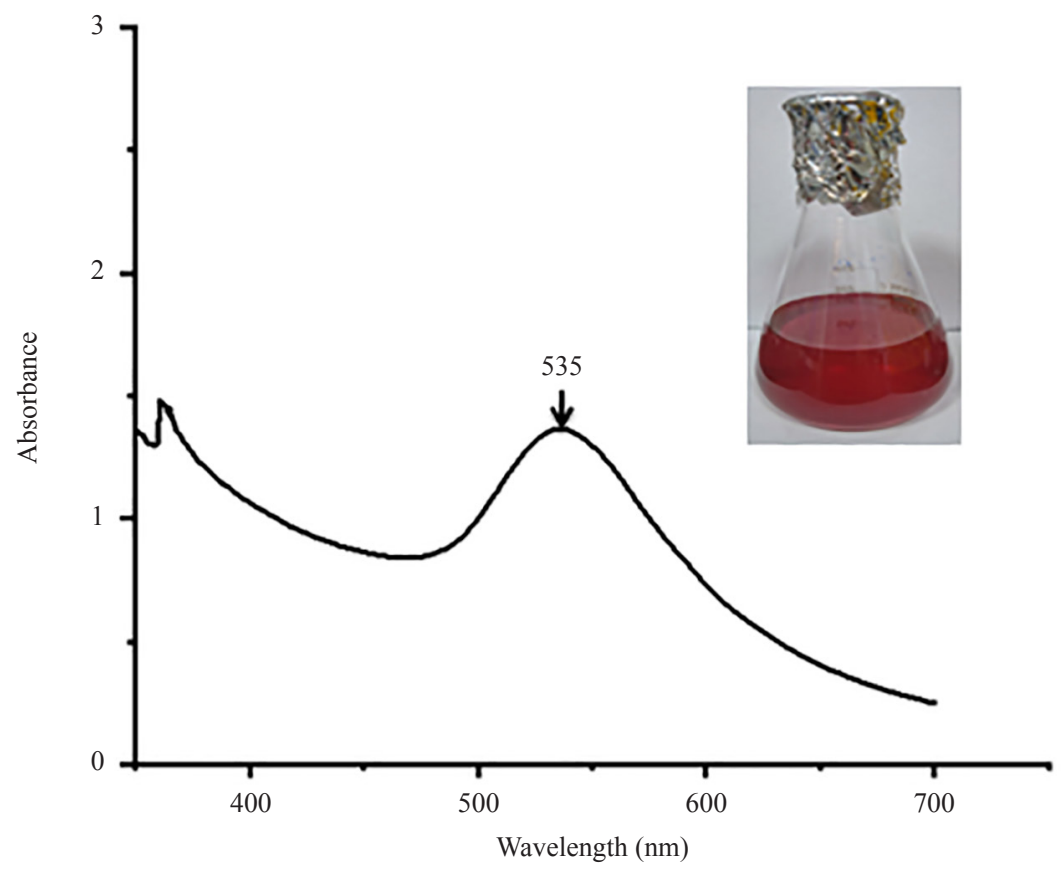

Figure 2. UV-Visible spectra of the myco-fabricated gold nanoparticles

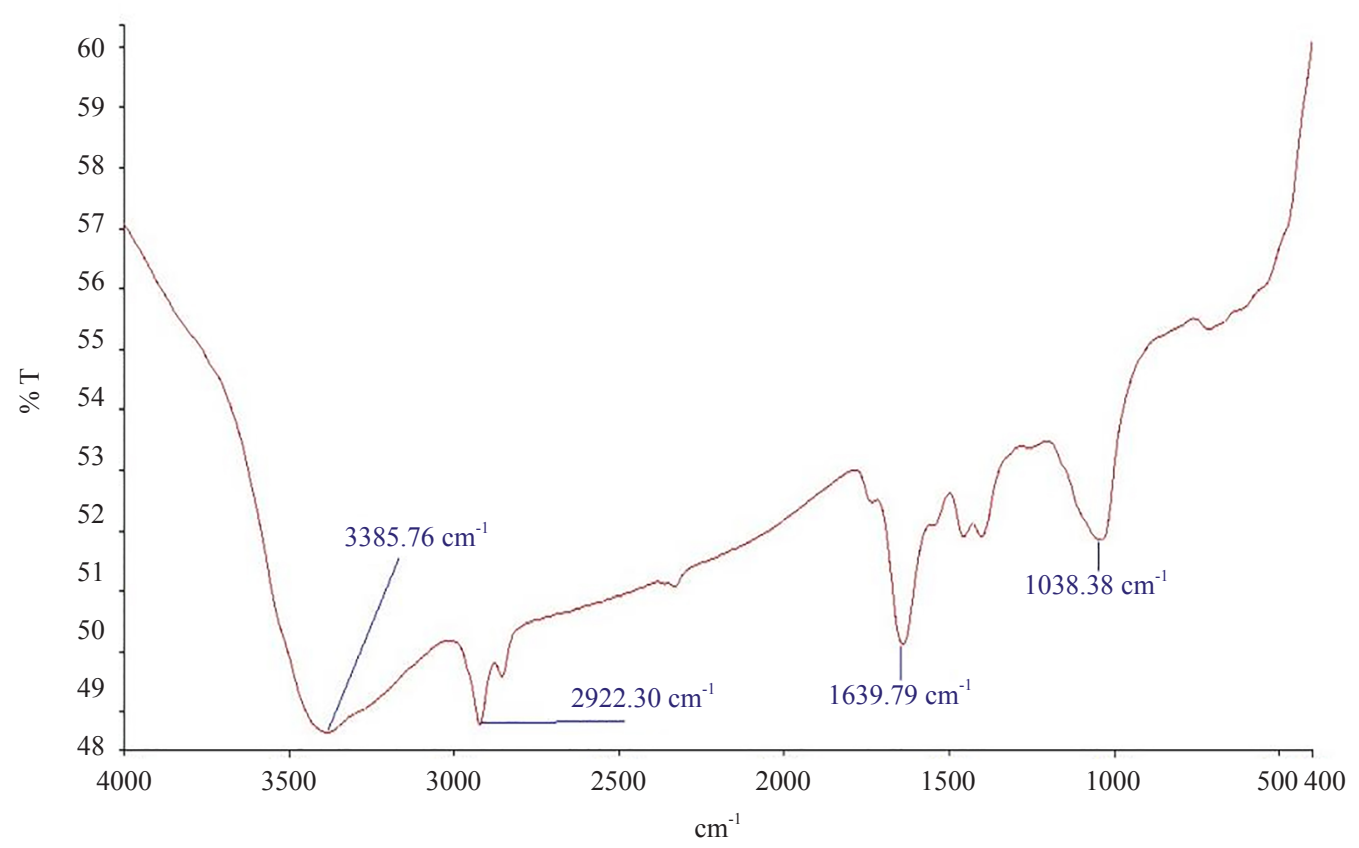

Figure 3. FTIR spectra of the myco-fabricated gold nanoparticles

The glass transition temperature of nanoparticles was observed at $226.76{ }^{\circ} \mathrm{C}$, as per the DSC analysis (Figure 4(a)), which was much higher compared to the phyto-synthesized gold nanoparticles observed by us [32]. This result suggests a possible angle where myco-synthesized gold nanopartilces are more stable compared to phytosynthesized nanoparticles.

A linear loss of the nanoparticles between the temperature range of 250 to $550{ }^{\circ} \mathrm{C}$, with the initial weight loss by 
TGA study at $139.33{ }^{\circ} \mathrm{C}$ (Figure 4(b)) is attributed to the loss of inherent water content. Finally a, residue of around $65.67 \%$ remained, which can be attributed to the left over gold nanoparticles after removal of the multiple layers of capping done by the extract [33].
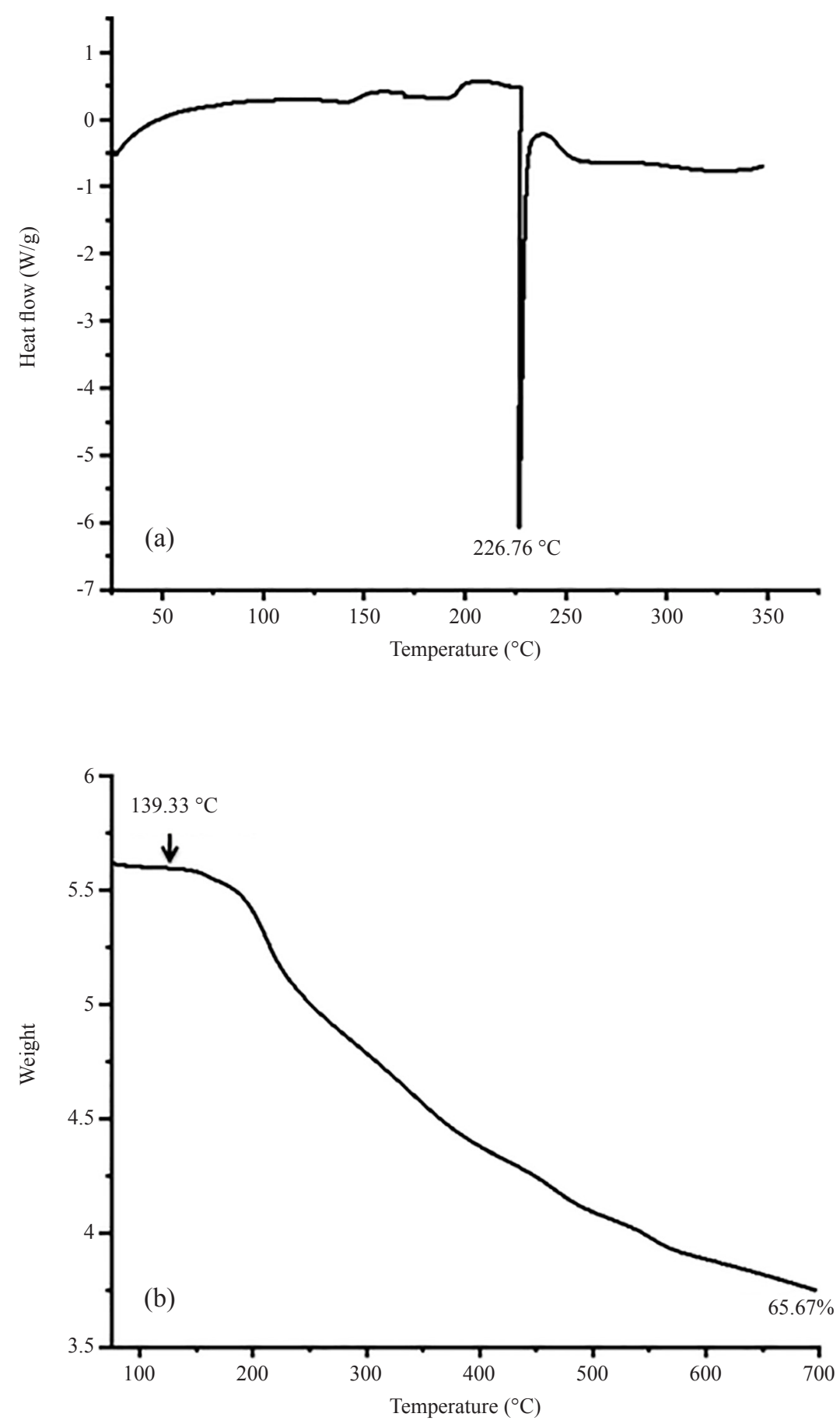

Figure 4. (a) DSC (b) TGA of gold nanoparticles

The hydrodynamic analysis of the particle size distribution of AuNPs varied from 80 to $137 \mathrm{~nm}$ and the average 
size (Z-average) was found to be $39.15 \mathrm{~nm}$, as shown in Figure 5, and zeta potential of $10.5 \mathrm{mV}$, as shown in Figure 6. Zetapotential value provides critical knowledge with respect to the stability of the nanopartilces. Here, the negative value of the zeta potential depicts the repulsion of the particles, illustrating the stability, whereby the agglomeration of the particles is avoided [34]. The SEM analysis illustrates the presence of crystallized rod-shaped structures (29) with an average size range of 55 to $91 \mathrm{~nm}$ (Figure 7).

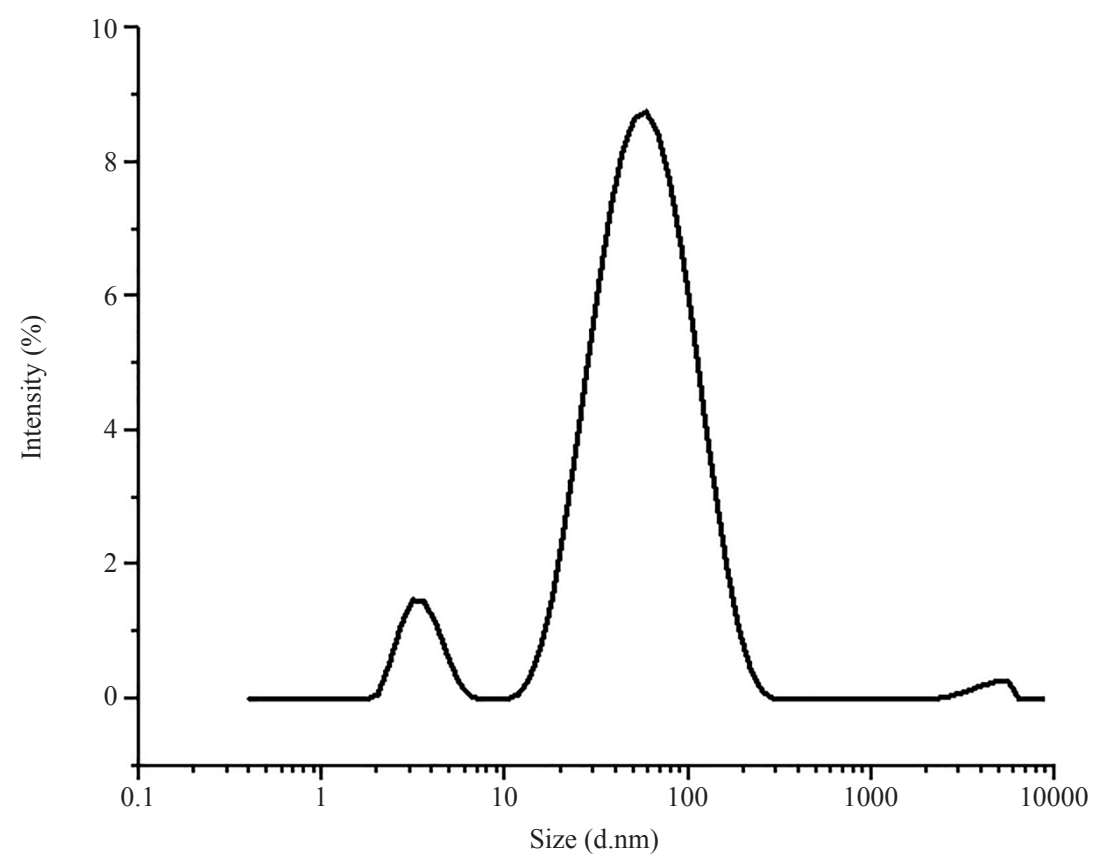

Figure 5. Particle size distribution showing $\mathrm{z}$ average of the gold nanoparticles

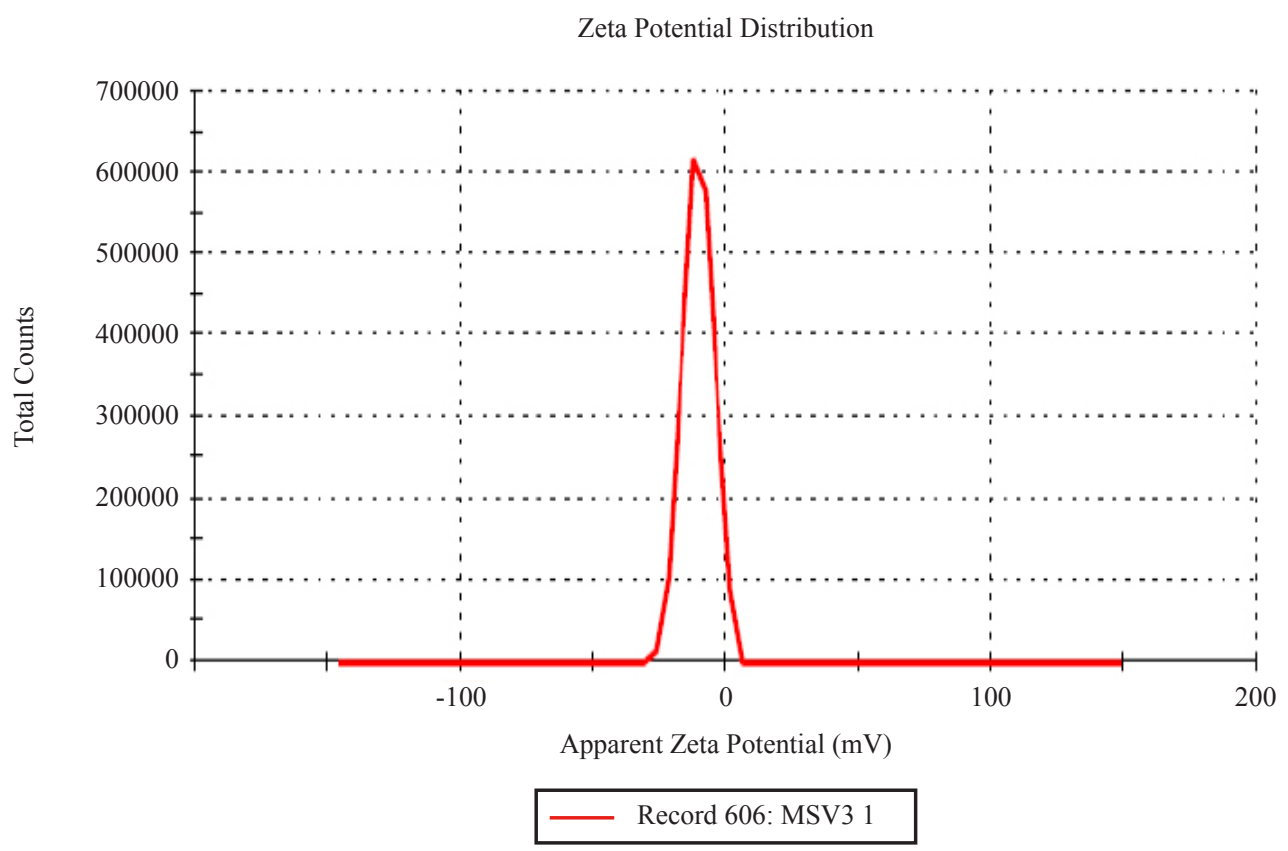

Figure 6. Zeta potential of the gold nanoparticles 


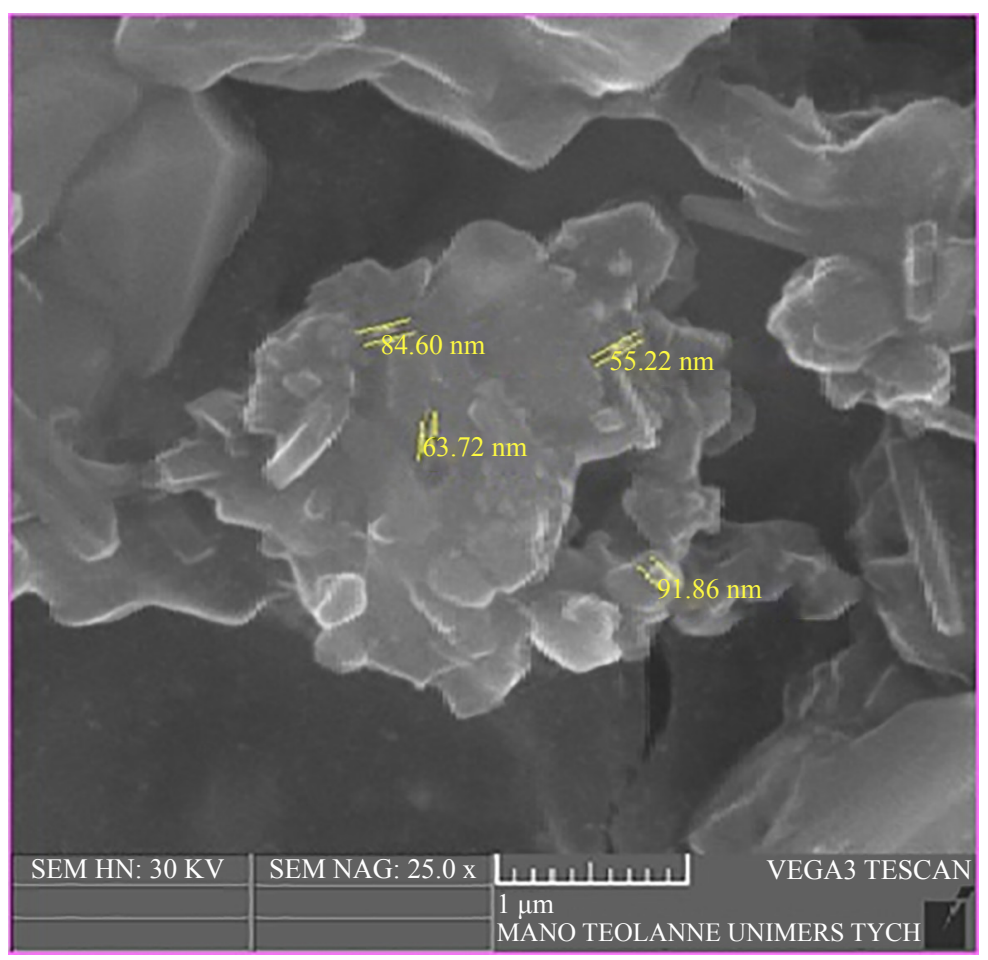

Figure 7. SEM image showing the presence of rod-shaped gold nanoparticles

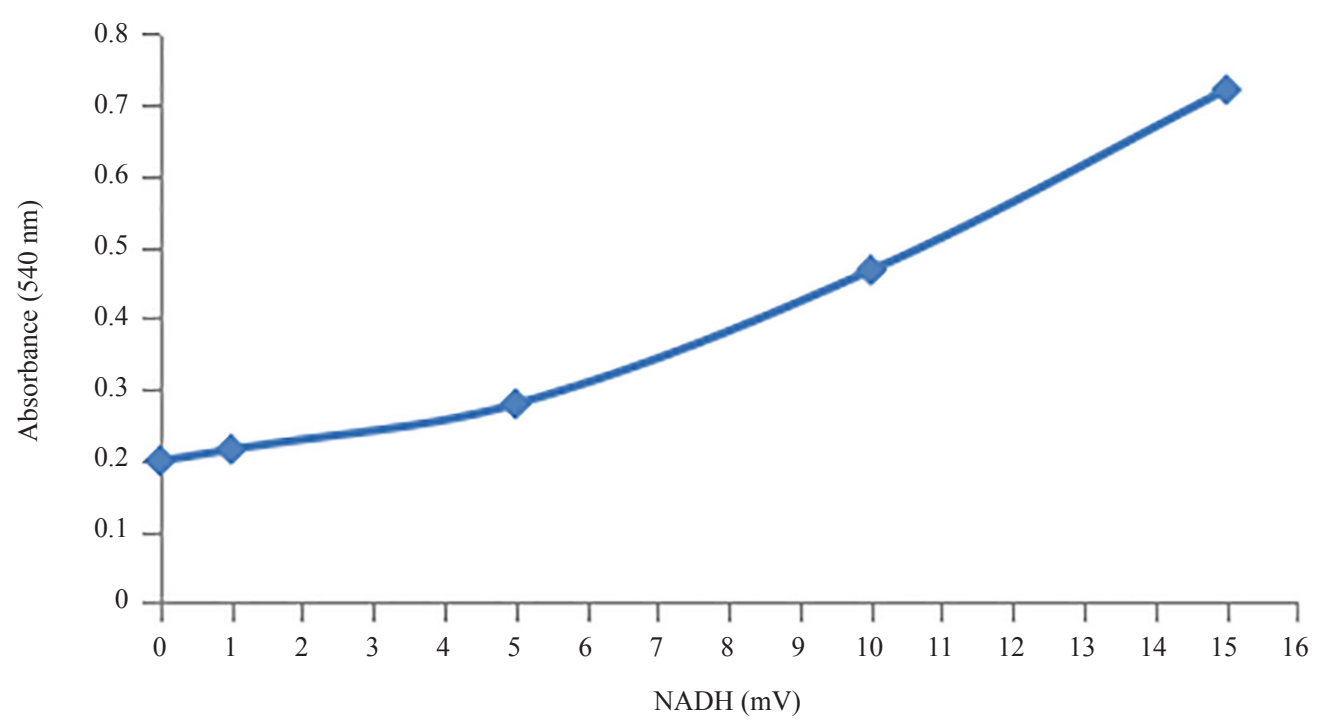

Figure 8. Enzymatic $\mathrm{Au}^{3+}$ reduction by Aspergillus tamarii (OD $540 \mathrm{~nm}$ )

Several mechanisms are described with respect to the green synthesis of gold nanoparticles. The common mechanism is that the metal ions are captured and reduced inside the microbial cell with the help of enzymes. The key role is played by the nitrate reductase enzymes, including NADH and NADPH-dependent enzymes, which brings about the bio-reduction process [14, 23, 35-36]. In the present study, the extract of $A$. tamarii MTCC 5152 was able to reduce $\mathrm{HAuCl}_{4}$, which was observed visually by their subsequent change in color, on increasing the concentration of NADH from 0 to $15 \mathrm{mM}$ (Figure 8). Similarly, the involvement of NADH-dependent reductases in the microbial synthesis of 
silver nanoparticles by F. oxysporum and P. fellutanum are also reported [31]. These observations might turn out to be of great contribution in the development of an uninterrupted biological production of nanoparticles on a large scale, with the addition of NADH or coupled with the regenerating system of co-enzymes.

The photocatalytic activity of gold nanoparticles was assessed by using the degradation of crystal violet, taken as the model dye. It is observed that the gold nanoparticles show strong absorption bands in visible region due to the phenomenon of surface plasmon resonance [37]. The crystal violet solution shows characteristic absorbance at $580 \mathrm{~nm}$. The visible change in solution color intensity from a deep violet color to a pale color indicated the dye degradation, which was analyzed by using UV-Visible spectrum, while the control remained unchanged. The doping concentration, the morphology of the catalyst, crystallinity and particle size are responsible for photocatalysis [38]. The photocatalytic degradation of dye is based on the differences in the conduction band of electrons. On irradiation through UV/Vis rays, the valence band electrons are up-regulated to the conduction band, leaving behind holes. Interaction of these electrons and holes with the nanoparticles triggers the catalytic action of NPs, thus enabling them to degrade the dye molecules [39]. This higher activity is hypothesized to be due to the functional groups such as hydroxyl groups on the surface of the NPs, which act as strong oxidants and promote interaction between electrons and holes.

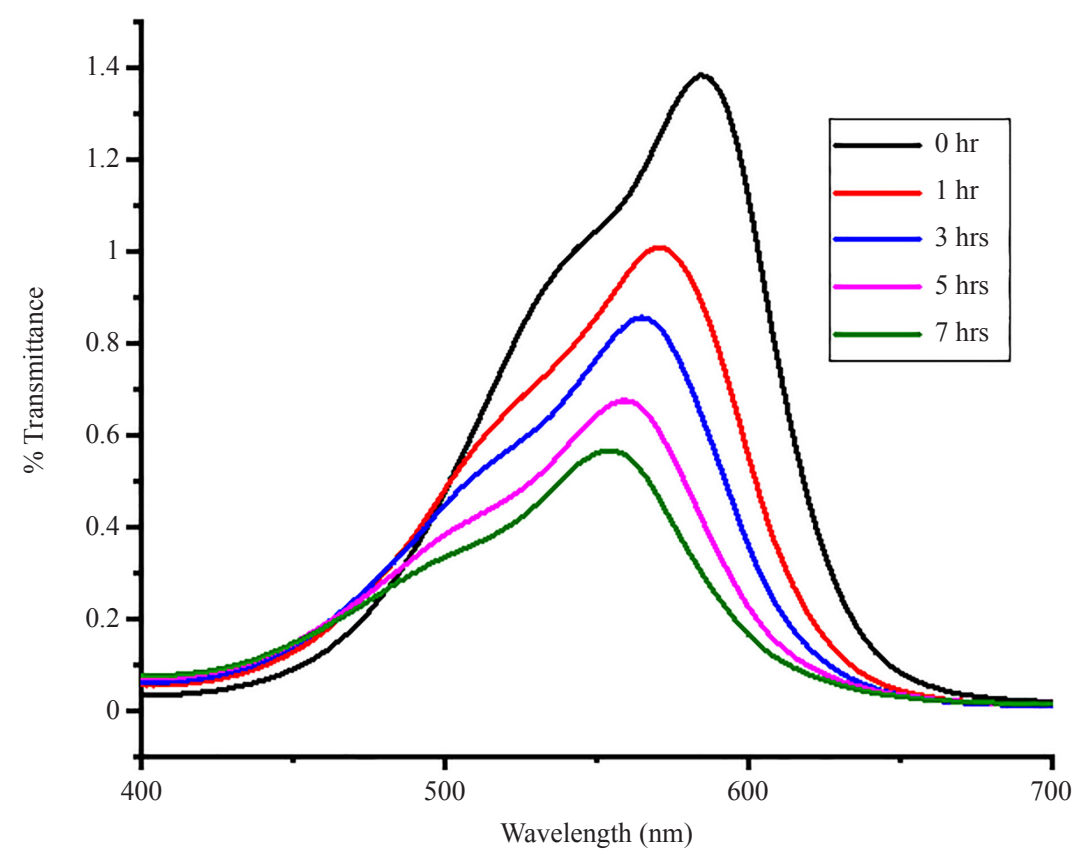

Figure 9. UV-Visible spectra showing decrease in absorbance of dye with time

From the absorbance values, the amount of dye degraded by the synthesized AuNPs was calculated to be $63 \%$ (Figure 9). Our previous study suggests that the catalytic degradation activity of the nanoparticles solely depends on the characteristics such as size, shape and structure of the metal nanoparticles [40].

\section{Conclusion}

In this work, we have presented the fungal-mediated synthesis of gold nanoparticles, wherein the fungal extract of A. tamarii MTCC 5152 has demonstrated its potential to reduce auric chloride. The study describes a more convenient and a relatively friendly way in order to synthesize gold nanoparticles. The mycogenic gold nanoparticles on subjecting to basic characterization studies including UV-Visible spectroscopy, FTIR analysis affirmed the presence of gold nanoparticles. The synthesized gold nanoparticles are found to be thermally stable and SEM imaging illustrated 
crystalline rod-shaped appearance of the gold nanoparticles. The myco-fabricated gold nanoparticles also depend on NADH as a co-factor for biological transformation and photocatalysis. The study concludes that A. tamarii MTCC 5152 could potentially be applied for the synthesis of gold nanoparticles in a cost effective and ecofriendly approach with dye biodegradation application.

\section{Conflict of interest statement}

We declare that we have no conflict of interest.

\section{Acknowledgements}

The authors acknowledge Council of Scientific and Industrial Research, New Delhi for financial assistance as an In-house project.

\section{References}

[1] Agnihotri M, Joshi S, Kumar A, Zinjarde S, Kulkarni S. Biosynthesis of gold nanoparticles by the tropical marine yeast Yarrowia lipolytica NCIM 3589. Materials Letters. 2009; 63: 1231-1234.

[2] Ahmad A, Mukherjee P, Mandal D, Senapati S, Khan MI, Kumar R, et al. Enzyme mediated extracellular synthesis of CdS Nanoparticles by the Fungus. Fusarium oxysporum. American Chemical Society. 2002; 124(41): 1210812109. Avaiblable from: https://doi.org/10.1021/ja027296o.

[3] Anjana KV. Exploration on green synthesis of gold nanoparticles by a marine-derived fungus Aspergillus sydowii. Environmental Progress and Sustainable Energy. 2015; 34(1): 194-197. Avaiblable from: https://doi.org/10.1002/ ep.11949.

[4] Boisselier E, Astruc D. Gold nanoparticles in nanomedicine: preparations, imaging, diagnostics, therapies, and toxicity. Chemical Society Reviews. 2009; 38: 1759-1782.

[5] Castro ME, Molina R, Díaz W, Pichuantes SE, Vásquez CC. The dihydrolipoamide dehydrogenase of Aeromonas caviae ST exhibits NADH-dependent tellurite reductase activity. Biochemical and Biophysical Research Communications. 2008; 375(1): 91-94. Avaiblable from: https://doi.org/10.1016/j.bbrc.2008.07.119.

[6] Chauhan A, Zubair S, Tufail S, Sherwani A, Sajid M, Raman SC, et al. Fungus-mediated biological synthesis of gold nanoparticles: Potential in the detection of liver cancer. International Journal of Nanomedicine. 2011; 6: 2305-2319. Avaiblable from: https://doi.org/10.2147/ijn.s23195.

[7] Donda MR, Kudle KR, Alwala J, Miryala A, Sreedhar B, Rudra MPP. Synthesis of silver nanoparticles using extracts of Securinega leucopyrus and evaluation of its antibacterial activity. International Journal of Current Science. 2013; 7: 1-8.

[8] Dong S, Zhou S. Photochemical synthesis of colloidal gold nanoparticles. Material Science and Engineering: B: Solid-State Materials for Advanced Technology. 2007; 140(3): 153-159. Avaiblable from: https://doi.org/10.1016/ j.mseb.2007. 03.020.

[9] Du L, Xian L, Feng J. Rapid extra/intracellular biosynthesis of gold nanoparticles by the fungus Penicillium sp. Journal of Nanoparticle Research. 2011; 13: 921-930. Available from: https://doi.org/10.1007/s11051-010-0165-2.

[10] Dykman LA, Bogatyrev VA. Gold nanoparticles in biology and medicine: Recent advances and prospects. Russian Chemical Reviews. 2007; 76: 181-194.

[11] Dykman LA, Bogatyrev VA, Shchegolev S, Khlebtsov NG. Gold nanoparticles: synthesis, properties, and biomedical applications. Moscow: Nauka; 2008.

[12] Gericke M, Pinches A. Microbial production of gold nanoparticles. Gold Bullet. 2006; 39: 22-28. Avaiblable from: https://doi.org/10.1007/BF03215529.

[13] Hsu S, Lin IJB. Synthesis of gold nanosheets through thermolysis of mixtures of long chain 1-Alkylimidazole and hydrogen tetrachloroaurate(III). Journal of Chinese Chemical Society. 2009; 56: 98-106.

[14] Huang J, Li Q, Sun D, Lu Y, Su Y, Yang X, et al. Biosynthesis of silver and gold nanoparticles by novel sundried Cinnamomum camphora leaf. Nanotechnology. 2007; 18: 105104-105115. 
[15] Hussein AM. Synthesis of some new purine-related compounds: Regioselective one-pot synthesis of new tetrazolo [1,5-a] pyrimidine, pyrazolo [1,5-a] pyrimidine and pyrimido [1,6-a] pyrimidine derivatives. Journal of Saudi Chemical Society. 2010; 14(1): 61-68. Available from: https://doi.org/10.1016/j.jscs.2009.12.010.

[16] Ipsita C, Pradeepam RJ, Kundu K, Singh PK, Kundu S. Mycofabrication of gold nanoparticles and evaluation of their antioxidant activities. Current Pharmaceutical Biotechnology. 2015; 16(8): 747-755. Available from: https:// doi.org/10.2174/138920101608150603160620.

[17] Ismail EH, Saqer AA, Assirey E, Naqvi A, Okash RM. Successful green synthesis of gold nanoparticles using a Corchorus olitorius extract and their antiproliferative effect in cancer cells. International Journal of Molecular Sciences. 2018; 19(9): 2612. Available from: https://doi.org/10.3390/ijms19092612.

[18] Kitching M, Ramani M, Marsili E. Fungal biosynthesis of gold nanoparticles: mechanism and scale up. Microbial Biotechnology. 2015; 8: 904-917.

[19] Kumar RR, Priyadharsani KP, Thamaraiselvi K. Mycogenic synthesis of silver nanoparticles by the Japanese environmental isolate Aspergillus tamari. Journal of Nanoparticle Research. 2012; 14: 860-866. Available from: https://doi.org/10.1007/s11051-012-0860-2.

[20] Kunwong D, Sumanochitraporn N, Kaewpirom S. Curing behavior of a UV-curable coating based on urethane acrylate oligomer: the influence of reactive monomers. Journal of Science and Technology. 2011; 33(2): 201-207. Available from: http://rdo.psu.ac.th/sjstweb/journal/33-2/0125-3395-33-2-201-207.

[21] Liu W, Yang X, Xie L. Size-controlled gold nano colloids on polymer microsphere-stabilizer via interaction between functional groups and gold nano colloids. Journal of Colloid and Interface Science. 2007; 313(2): 494502. Available from: https://doi.org/10.1016/j.jcis.2007.04.055.

[22] Mao Z, Espinoza R, Garcia A, Enwright A, Vang H, Nguyen SC. Turning redox potential of gold nanoparticles photocatalysts by light. ACS Nano. 2020; 14(6): 7038-7045. Available from: https://doi.org/10.1021/ acsnano.0c01704.

[23] Menon S, Rajeshkumar S, Kumar SV. A review on biogenic synthesis of gold nanoparticles, characterization, and its applications. Resource-Efficient Technologies. 2017; 3(4): 516-527. Available from: https://doi.org/10.1016/ j.reffit.2017.08.002.

[24] Mukherjee P, Senapati S, Ahmad A, Khan MI, Sastry M. Extracellular synthesis of gold nanoparticles by the fungus Fusarium oxysporum. Chem BioChem. 2002; 3(5): 461-463. Available from: https://doi.org/10.1002/14397633(20020503)3:5<461::AID-CBIC461>3.0.CO;2-X.

[25] Netala VR, Kotakadi V, Bobbu P, Gaddam SA, Tartte V. Endophytic fungal isolate mediated biosynthesis of silver nanoparticles and their free radical scavenging activity and anti-microbial studies. 3 Biotech. $2016 ; 6(2)$ : 132. Available from: https://dx.doi.org/10.1007\%2Fs13205-016-0433-7.

[26] Chow PE. Gold Nanoparticles: Properties, Characterization and Fabrication. Nova Science Publisher; 2010. Available from: https://doi.org/978-1-61668-009-1.

[27] Pasha A, Syed B, Devaraju R, Sreedharamurthy S. Mycosynthesis of silver nanoparticles bearing antibacterial activity. Saudi Pharmaceutical Journal. 2016; 24(2): 140-146. Available from: https://doi.org/10.1016/ j.jsps.2015.01.008.

[28] Priyadarshini E, Pradhan N, Sukla LB, Panda PK. Controlled synthesis of gold nanoparticles using aspergillus terreus IF0 and its antibacterial potential against Gram Negative Pathogenic Bacteria. Journal of Nanotechnology. 2014; 2014: 1-9. Available from: http://dx.doi.org/10.1155/2014/653198.

[29] Soni N, Prakash S. Synthesis of gold nanoparticles by the fungus Aspergillus niger and its efficacy against mosquito larvae. Reports in Parasitology. 2012; 2: 1-7. Available from: https://doi.org/10.2147/RIP.S29033.

[30] Ravichandran V, Vasanthi S, Shalini S, Shah SA, Tripathy M, Paliwal N. Green synthesis, characterization, antibacterial, antioxidant and photocatalytic activity of Parkia speciosa leaves extract mediated silver nanoparticles. Results in Physics. 2019; 15: 102565. Available from: https://doi.org/10.1016/j.rinp.2019.102565.

[31] Riabinina D, Zhang J, Chaker M, Margot J, Ma D. Size control of gold nanoparticles synthesized by laser ablation in liquid media. ISRN Nanotechnology. 2012; 2012: 297863. Available from: https://doi.org/10.5402/2012/297863.

[32] Sanghi R, Verma P, Puri S. Enzymatic formation of gold nanoparticles using Phanerochaete chrysosporium. Advances in Chemical Engineering and Science. 2011; 1(3): 154-162. Available from: https://doi.org/10.4236/ aces.2011.13023.

[33] Senapati S, Ahmad A, Khan MI, Sastry M, Kumar R. Extracellular biosynthesis of bimetallic Au-Ag alloy nanoparticles. Small. 2005; 1(5): 517-520. Available from: https://doi.org/10.1002/smll.200400053.

[34] Singh J, Dutta T, Kim K, Rawat M, Samddar P, Kumar P. 'Green' synthesis of metals and their oxide nanoparticles: applications for environmental remediation. Journal of Nanobiotechnology. 2018; 16: 84. Available from: https:// doi.org/10.1186/s12951-018-0408-4. 
[35] Vasantharaj S, Sripriya N, Shanmugavel M, Manikandan E, Gnanamani A, Senthilkumar P. Surface active goldnanoparticles biosynthesis by new approach for bionanocatalytic activity. Journal of Photochemistry and Photobiology B. 2018; 179: 119-125.

[36] Vasantharaj S, Sathiyavimal S, Saravanan M, Senthilkumar P, Gnanasekaran K, Shanmugavel M, et al. Synthesis of ecofriendly copper oxide nanopartilces for fabrication over textile fabrics: Characterization of antibacterial activity and dye degradation potential. Journal of Photochemistry and Photobiology B: Biology. 2019; 191: 143149. Available from: https://doi.org/10.1016/j.jphotobiol.2018.12.026.

[37] Verma VC, Kharwar RN, Singh SK, Solanki R, Prakash S. Correction to biofabrication of anisotropic gold nanotriangles using extract of endophytic Aspergillus clavatus as a dual functional reductant and stabilizer. Nanoscale Research Letters. 2011; 6(1): 261. Available from: https://dx.doi.org/10.1186\%2F1556-276X-6-261.

[38] Behnajady MA, Modirshahla N, Hamzavi R. Kinetic study on photocatalytic degradation of C.I.Acid Yellow 23 by $\mathrm{ZnO}$ photocatalyst. Journal of Hazardous Materials. 2006; 133(1-3): 226-232. Available from: https://doi. org/10.1016/j.jhazmat. 2005.10.022.

[39] Han S, Hu L, Gao N, Al-Ghamdi AA, Fang X. Efficient self-assembly synthesis of uniform CdS spherical nanoparticles-Au nanoparticles hybrids with enhanced photoactivity. Advanced Functional Materials. 2014; 24(41): 6412-6412. Available from: https://doi.org/10.1002/adfm.201400012.

[40] Wilson R. The use of gold nanoparticles in diagnostics and detection. Chemistry Society Reviews. 2008; 37(9): 2028-2045. Available from: https://doi.org/10.1039/b712179m. 